\title{
Last planner system application in Recursos Norte project commissioning, El Teniente mine
}

\author{
A Fernández University of Santiago of Chile, Chile \\ B Trigo CODELCO, Chile
}

S Aránguiz Gardilcic Construction, Chile

\begin{abstract}
The Recursos Norte project is one of the three new projects under construction at El Teniente Mine aimed at maintaining copper production over the next five years. The project is located north of the currently productive sectors Dacita and Reservas Norte. Inside the management area responsible for project development and construction, the planning area was created to ensure milestones occurred according to the five-year plan of El Teniente, and to do so, the Last Planner System (LPS) methodology was applied, using planning cycle criteria for annual, quarterly, monthly, weekly, 36-hour and daily plans. Because mining through the Panel Caving method considers a large number of variables at the same time and interactions need to be managed among different construction companies, one of the primary challenges is coordination of project activities. The initial phase involved the development of tunnels and mining construction for the four productive levels executed within approximately $80,000 \mathrm{~m}^{2}$. This paper details the cycles, results and benefits obtained from the application of LPS during the construction phase of the project, analyzing the variation of the main key performance indicators (KPIs), implementation of standards for the different activities of the construction cycle, and planning and continuous improvement sessions (Lean Construction tools) held with the project stakeholders. As a main conclusion of the work, through the application of LPS, the commissioning of the project was achieved 15 months prior to the date established in the original plan, i.e. rather than in December 2020, commissioning occurred in September 2019. Finally, substantial improvements related to the effective management of the planning area were obtained: validated and agreed upon periodic plans regarding activity execution, increased effective work time, improved control and monitoring tools, and increased participation of stakeholders in key activities. These improvements generated collaboration with the different areas, companies, and management within El Teniente mine with a focus on the professionalization of mining construction activities and sustainability of the process.
\end{abstract}

\section{Introduction}

At El Teniente mine, three new projects are under construction, which are based on the Panel Caving Method and whose objective is to maintain the company's level of copper production. Given the large volume of construction and the associated budgets, El Teniente defined and positioned mine preparation as one of its priority objectives in its strategic planning (Morales \& Díaz 2008). Therefore, the Mine Preparation Area was created to manage the development planning for these new projects.

According to the engineering studies and the long-term planning, the Recursos Norte's project was set to be the first to start production with commissioning in December 2020, followed by the Diamante and Andesita projects with commissioning in 2023 and 2024, respectively. In 2016, the exploration developments and construction of the main accesses to the production levels of the projects (initial developments) were executed for Recursos Norte, whilst for Diamante and Andesita these initial developments were executed in 2018. During this construction phase, one construction company executed a set of tunnels and mine infrastructure within the same area to be shared amongst the three projects, 
and upon which the construction company had to report to each project director. In the same context, the main service and transport route availability was highly variable because the routes were shared with other mine sectors. To integrate contractor management into the business and achieve sustainability in development by reducing construction time, the Mine Preparation Area started to incorporate key concepts of the Lean Construction (LC) philosophy in their planning process. Concepts such as First Run Studies (FRS), increased visualization, and productive meetings were applied in early stages of the project, while concepts such as LPS, root cause analysis/ five "whys" and concurrent engineering were implemented during the construction phase. Of these concepts, LPS was the most relevant and used as a basis to define the planning cycle for mine preparation. The mine's Operational Excellence Area served as advisors during this implementation process.

\subsection{Hypothesis and objectives}

By establishing a coupling strategy between the Recursos Norte project and the Reservas Norte mine, it was hypothesized that using LPS in the construction phase as a continuous improvement methodology could advance the commissioning of the Recursos Norte project by 15 months (from December 2020 to September 2019). As a consequence of the coupling strategy with the project Reservas Norte, the following were the main assumptions:

- The direction in the caving front could be changed to allow caving to reach the first drawbell in November 2019.

- The first drawbell could be undercut in May 2019 considering the current advance rate of the Reservas Norte project.

- Completion of all the developments and constructions inside the defined halo on the caving front could be feasible by September 2019.

Achieving the main objective of bringing forward the commissioning would require the application of the LPS and LC tools in the execution of the mining construction of Recursos Norte and would involve multidisciplinary teamwork among the different areas and stakeholders of the project.

\section{Scope and specification on the project construction phase}

\subsection{Recursos Norte Project background}

The Recursos Norte Project is located north of the Dacita and Reservas Norte production sectors. Its reserves are approximately $132 \mathrm{Mt}$ with an average grade of $0.74 \%$ projected to reach a production rate of $30 \mathrm{Kton} /$ day with a duty life of 20 years. The mining method used will be the conventional panel caving method with preconditioning. Figure 1 shows the mining design of the production levels and the main design parameters for each. The direction of the caving front and the progression of mine preparation are to the northeast.

Subsequently, the project considered a variation in its strategy regarding the direction of the caving front. This variation resulted from coupling of Recursos Norte with the production of the Reservas Norte sector, which affected the scope of the infrastructure and construction work and thus the initial investment scope of the contracts. In addition, mining construction work in the production levels was divided in two contracts both executed by one construction company.

- Contract one (C1): Mining construction work in the undercut and extraction levels and initial developments for the Diamante project.

- Contract two (C2): Mining construction work in the ventilation and haulage levels and exploration and early development work for the Andesita project. 


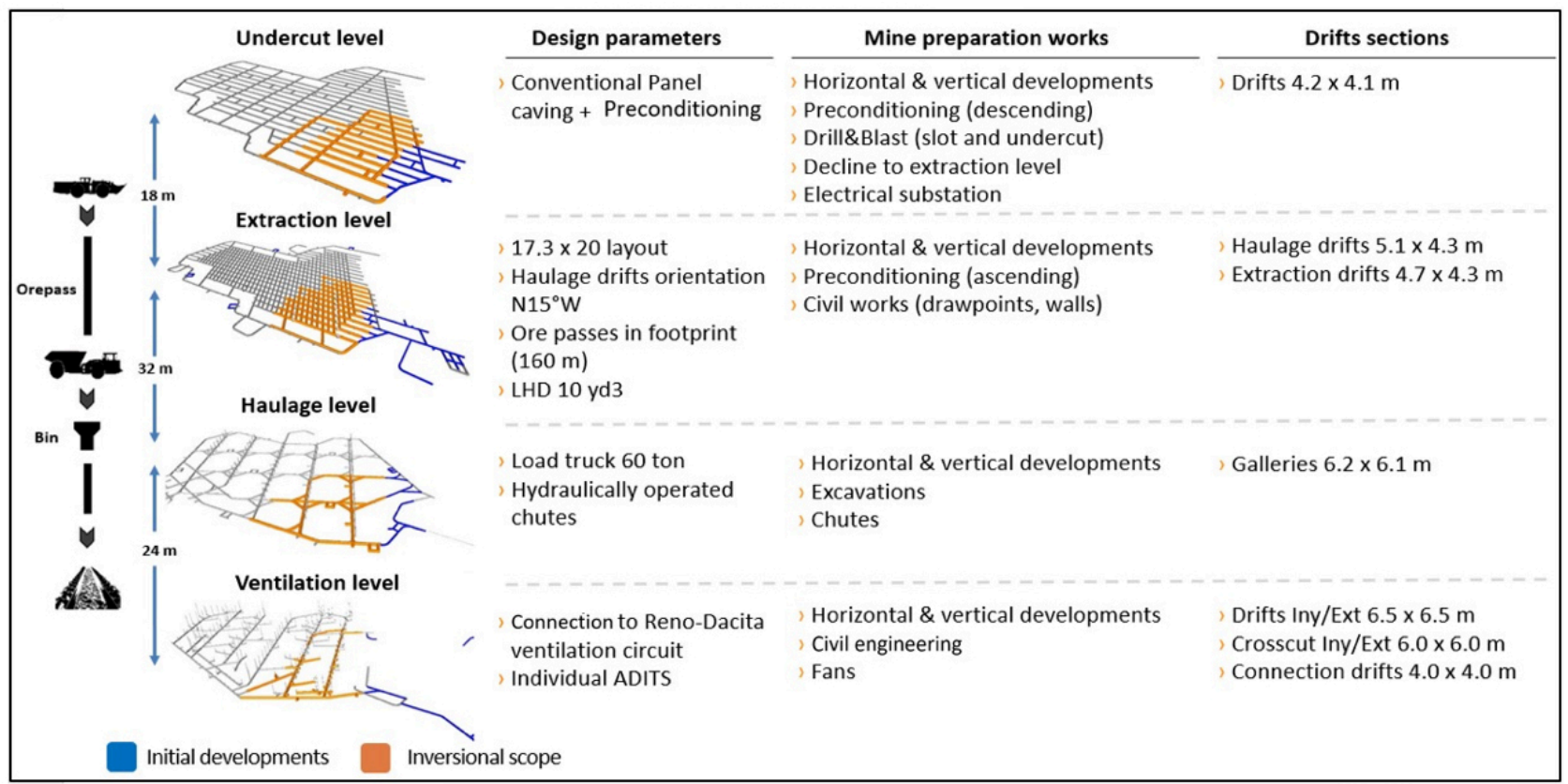

Figure 1 Mining design and specifications of the extraction levels from the project

\subsection{Commissioning of Recursos Norte's mine}

The coupling strategy with the Reservas Norte Project modified the progress of the caving front towards the $\mathrm{N} 600$ direction, which defined the first drawbell to be blasted as the one located on the draw point drift 32 between production drifts 16-17. As shown in Figure 2, this milestone also considered the mine development construction, civil engineering, and infrastructure for the area necessary ahead of the front. In addition, the planning and execution of construction support infrastructure according to the progress of the project was necessary in a halo of construction of more than 70,000 m2.

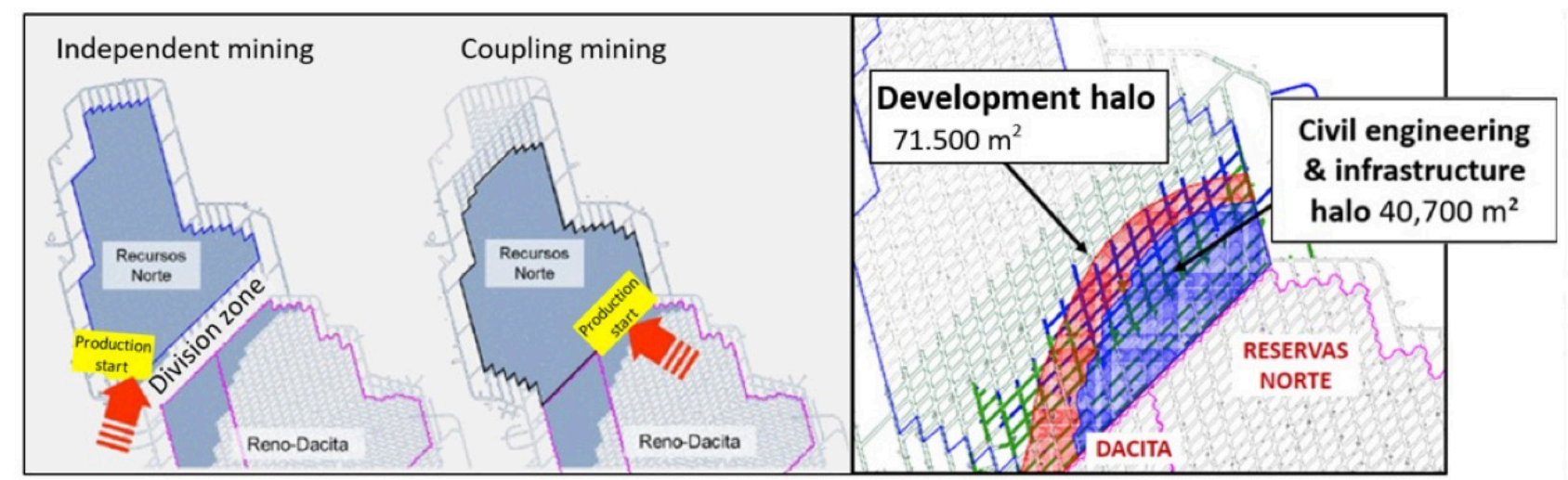

Figure 2 Coupling mining strategy. The red halo on the right plan indicates the scope of the developments and the blue halo of the infrastructure in the extraction level

According to the previously defined scope, it was established that the date of the commissioning could be modified from December 2020 to November 2019. This modification considered the current planning of drawbells to undercut, the caving area specified in the annual plan for all the production sectors in $\mathrm{El}$ Teniente mine, and the developments already completed ahead of the caving front of the Reservas Norte sector.

\subsection{Organizational structure of work}

For the execution of the mine preparation activities, specialized contractors had to work in a shared area and use the same transport routes and ventilation circuits. In this context, the main contractor for mine preparation also executed the initial developments for the Andesita and Diamante projects. Therefore, 
the resources and equipment could be shared among the three projects. Management of the different areas required constant discussion and review of the strategic planning for the productive sectors and for the new projects to reduce the interactions between the undercutting and development activities. On the other hand, constant supervision and assessments from different areas such as engineering, geology, geomechanics and ventilation, among others, demanded specific periodic meetings with the contractors to evaluate the performance and specified requirements.

Figure 3 shows an organizational scheme that specifies the relationships among the main stakeholders of the new projects. The scheme shows the projects have their own director and engineering area but share a common contractor to execute all the development activities, supported by other contractors for specialized activities. The Mine Preparation Area in the extraction level is also shared with other contractors that execute development and infrastructure activities corresponding to the continuity of the construction work for the Reservas Norte sector. The interactions among the different contractors' activities for the production sectors and the new projects were managed by the Mine Preparation Area or the Strategic Planning Area.

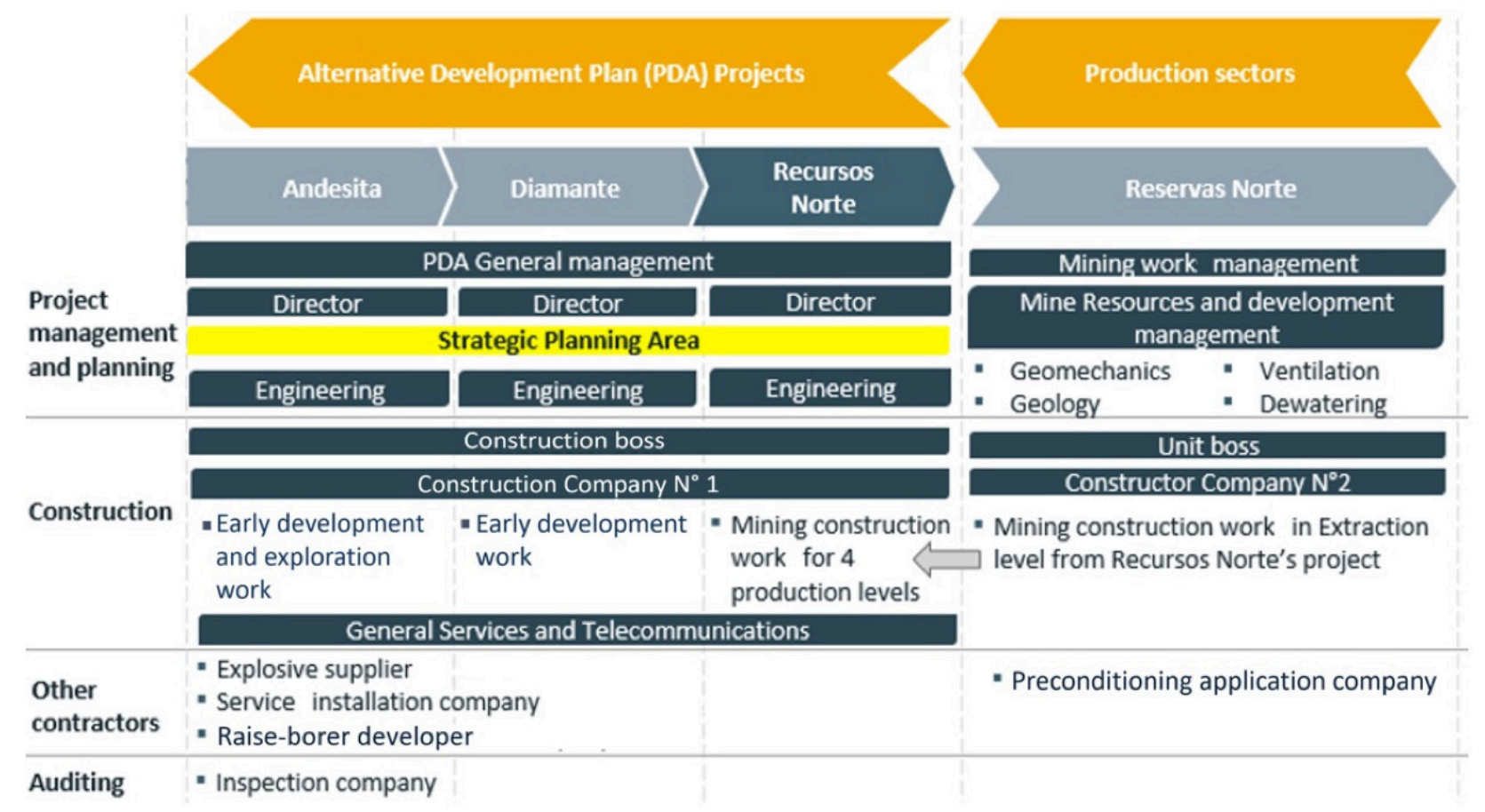

\section{Figure 3 Organizational scheme from Recursos Norte's stakeholders}

The planning area organization was set up such that the daily planners develop their tasks for controlling and monitoring the status of activities according to the monthly plan. They also lead the weekly meeting, manage restrictions, and elaborate the updated weekly plan. On the other hand, the medium-term planners elaborate the monthly plans, participate in the weekly meetings with different stakeholders, lead the pull planning sessions, elaborate and update the quarterly plan, and manage the intermediate milestones established in the annual plan.

\subsection{Scope of developments and infrastructure construction}

Table 1 summarizes the developments, civil construction and infrastructure established in the initial scope of mine preparation for the productive levels related to the initial investment approval for the project. This scope comprises the contracts C1, C2 and the work executed for mine management for the extraction level of the Reservas Norte sector. The defined area ahead of the caving front corresponds to 40,700 $\mathrm{m}^{2}$ of civil construction and infrastructure, and $71,500 \mathrm{~m}^{2}$ of developments. 
Table 1 Scope of developments and infrastructure in productive levels of the Recursos Norte's Project

\begin{tabular}{|c|c|c|c|}
\hline Production level & Developments & Infrastructure & Investment scope \\
\hline \multirow[t]{2}{*}{ Undercut } & \multirow[t]{2}{*}{$3,974 \mathrm{~m}$} & Muck ore passes & $5 \mathrm{u}$ \\
\hline & & Preconditioning & $8 u$ \\
\hline \multirow[t]{6}{*}{ Extraction } & \multirow[t]{6}{*}{$6,296 \mathrm{~m}$} & Ore pass excavation & $12 \mathrm{u}$ \\
\hline & & Drawpoints & $151 \mathrm{u}$ \\
\hline & & Walls & $160 u$ \\
\hline & & Preconditioning holes & $12 u$ \\
\hline & & Ore pass lining & $12 u$ \\
\hline & & Concrete slab & $1,855 \mathrm{Im}$ \\
\hline \multirow[t]{3}{*}{ Haulage } & \multirow[t]{3}{*}{$2,940 \mathrm{~m}$} & Chute construction & $8 \mathrm{u}$ \\
\hline & & Chute assembly & $8 u$ \\
\hline & & Concrete slab & $1,408 \mathrm{Im}$ \\
\hline \multirow[t]{3}{*}{ Ventilation } & \multirow[t]{3}{*}{$2,150 \mathrm{~m}$} & Purchase of fans & $16 u$ \\
\hline & & $\begin{array}{c}\text { Construction of fan } \\
\text { chamber }\end{array}$ & $13 u$ \\
\hline & & Fan commissioning & $13 u$ \\
\hline
\end{tabular}

\subsection{Mining construction management}

Mine preparation, specifically for Panel Caving must identify a large number of variables related to the execution of activities in permanent interaction and interdependence. The stakeholders should consider the influence of these variables on the work planning with a strategy of forward-looking management to reduce uncertainty in the assumptions. For the El Teniente Mine context, some of the specific variables that had to be managed by the planning team at the time as the periodic plans were being elaborated included the following:

- Progress of the Abutment Stress Zone (ASZ) according to the coupling with the Reservas Norte sector.

- New construction method (mechanized lining) for ore passes not previously used in the mine.

- Presence of muck in headings and drifts from previous developments of older contracts, which reduced the availability to manage the muck from actual developments to ore passes.

- Complex geomechanical conditions in the headings related to the progress of the ASZ and high stresses.

- Low contractor work standards and safety performance causing reduction in the effective time planned.

- Post blast and seismic isolations due to the proximity to the production sectors.

- Poor ventilation conditions in sectors due to low standards, considering, for example, tunnels blocked by the presence of muck not extracted according to plan.

\section{$3 \quad$ Last Planner System (LPS) methodology applied}

The Last Planner System is a short-term project planning system first used in engineering construction in the early 1990s that aims to improve the predictability and reliability of construction production (Ballard \& Howell 1998; Ballard 2000). For the construction industry, both for large and small projects, LPS is part of a new management system for one-off project-based production that allows project managers to 
improve productivity and client/end-user satisfaction. The system provides a structured series of plans and evaluation conversations aimed at assuring that a high percentage of key activities are completed on time and on budget. These conversations must be collaborative at the lowest possible level in the organization to create significant improvements in the project. Some of the benefits reported in construction projects are predictability, productivity, and speed of delivery, profit, and feelings of well being among project staff; the goal is to identify and solve issues before they become problems on-site (Mossman 2017).

Currently, five key conversations have been identified that are designed to allow the project team to collaboratively plan the sequence of work for each phase of the project:

1. Phase Planning: Sessions to help the project team get to know each other, identify issues with the project, and agree how to resolve them and design the solution.

2. Look Ahead: Sessions for the identification of issues ahead of the actual plan. This helps to ensure that the work can feasibly be executed on the dates established.

3. Commitment planning: Meetings to commit to responsibility and dates for completion of key activities, checking before for interdependencies to ensure the participation of the correct person/ people who claim responsibility.

4. Production management: Periodic sessions to adjust plans in the light of new information, collect information about the reasons for non-compliance, and identify the root cause.

5. Learning conversations: Encourage learning from both success and failure to reduce the risk of repeated failures.

Mine preparation, which corresponds to the construction phase of the project, involves many actors with high disciplinary interdependence; this includes owners, designers, and constructors. Developing synergy during the collaborative programming of project phases through a network of production relationships and promises between these actors enables delivery of quality projects on time. Furthermore, in mining construction it is crucial to make 'control' proactive by being sure things can be done when planned. In this context, the system's performance must be measured and improved with a view to managing and improving total project performance (Leal \& Alarcón 2010).

In the Recursos Norte project, LPS was introduced in the planning cycle by the Mine Preparation Area to achieve the commissioning milestone. For this, a specialized consulting company led the training for the professionals of the area, and the Operational Excellence Area provided support during the implementation phase. The objective was to provide the last planners, constructors and design-team leaders with the authority, information, and physical and social space they needed to make decisions collaboratively about the execution of activities.

\subsection{Planning cycle methodology}

Some problems at the beginning of the project, such as resistance to change, ignoring contractors' concerns, and constant firefighting, promoted the idea of incorporating a lean planning system. Central conversations of LPS were introduced and adapted to the medium- and short-term planning cycle to ensure compliance with the commissioning through effective management at all levels of the organization. As Figure 4 shows, based on the main conversations of LPS, the cycle advanced from a master plan focused on the commissioning to the Plan of Day (POD) meetings, also considering First Run Studies (FRS) - sessions with the stakeholders of the project to simulate critical scenarios and understand where failures might occur so that robust alternatives can be planned. The cycle advanced during the milestone, planning and look ahead planning phases, and a continued process of learning and improving was also part of the process. Each plan is detailed in the next sections. 


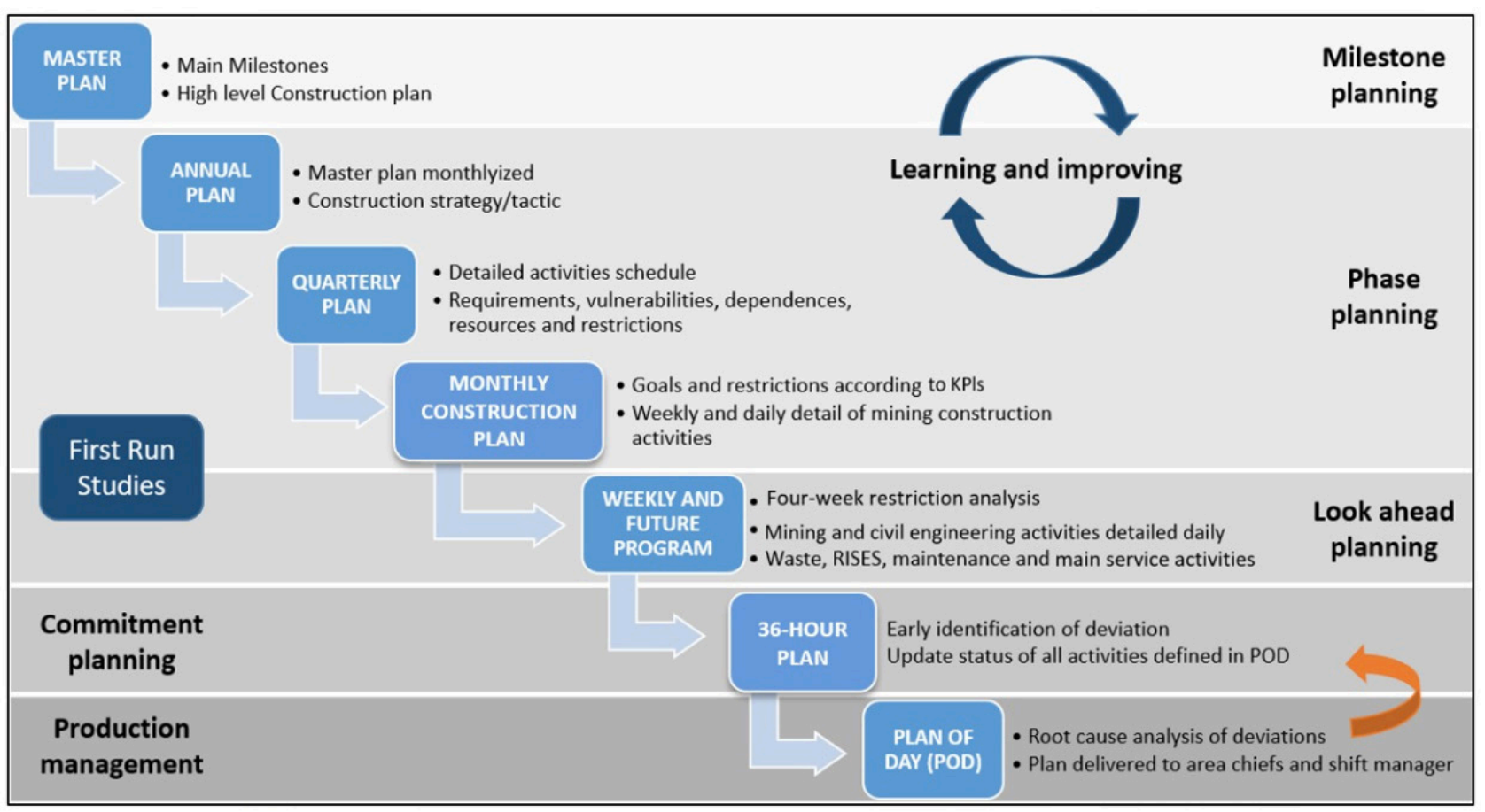

Figure 4 Planning cycle criteria used based on LPS

\subsubsection{Master plan}

The main objective corresponded to advancing the commissioning of the project, which implied the construction of the necessary infrastructure and developments ahead of the caving front according to a conventional panel caving operation. This scope aimed to give continuity to the mine preparation after the coupling with Reservas Norte and the production started. This plan was elaborated from April to September 2019.

Initially, as mentioned in the introductory section, the dates set for commissioning in December 2020 were brought forward in relation to the sequence of drawbells to blast in the annual plan of El Teniente Mine. Then, First Run Studies (FRS) - sessions with the stakeholders to simulate critical scenarios and understand where failures might occur - were carried out to assess the feasibility of challenging the original date using LPS. Capacities and yields were analyzed and discussed to define the critical route of the project to change the commissioning to September 2019.

Additionally, the master plan specified the planning of other activities that were not part of the critical path of the project. This was done because all the activities and milestones considered by the plan are highly relevant to maintaining the continuity of the operation, avoiding interferences and deviations, and performing mine preparation activities outside the ASZ. Table 2 shows the key aspects of the master plan for the commissioning. 
Table 2 Main aspects of the commissioning for the Recursos Norte Project

\begin{tabular}{|c|c|c|}
\hline \multicolumn{2}{|r|}{ Caving } & Specifications \\
\hline \multicolumn{2}{|c|}{ Caving process } & $660 \mathrm{~m}^{2} /$ month additional between May/September \\
\hline \multicolumn{2}{|c|}{ Drawbell } & $4 \mathrm{u}$ additional drawbells between May/September \\
\hline \multicolumn{2}{|c|}{ Preconditioning } & 8 blast holes to drill and hydro-fracturing \\
\hline \multicolumn{2}{|c|}{ Construction } & Specifications \\
\hline Infrastructure & $\begin{array}{l}\text { - } \quad \text { Extraction level } \\
\text { - } \quad \text { Haulage level }\end{array}$ & $\begin{array}{c}\text { All work within the ASZ halo projected to September } \\
\text { must be constructed to separate from mining } \\
\text { developments }\end{array}$ \\
\hline $\begin{array}{l}\text { Mining } \\
\text { developments }\end{array}$ & - Four productive levels & $\begin{array}{c}\text { These are key to continue the advance of the } \\
\text { construction for the overall operational continuity of } \\
\text { the sector (see Figure 5). }\end{array}$ \\
\hline \multicolumn{2}{|c|}{ Main milestones } & Date \\
\hline \multicolumn{2}{|c|}{ Infrastructure constructions start in Z-35 } & June \\
\hline \multicolumn{2}{|c|}{ Preconditioning start } & Perforation: May; hydro-fracturing: June \\
\hline \multicolumn{2}{|c|}{ Ore pass construction start } & June 4 \\
\hline \multicolumn{2}{|c|}{ Vulnerabilities } & Condition \\
\hline \multicolumn{2}{|c|}{ headings development at ventilation level } & High water presence and large haulage distances \\
\hline \multicolumn{2}{|c|}{ headings development at haulage level } & $\begin{array}{c}\text { Difficulty in construction according to geotechnical } \\
\text { conditions }\end{array}$ \\
\hline \multicolumn{2}{|c|}{ Ore pass construction in haulage level } & $\begin{array}{l}\text { New method of construction not previously used in El } \\
\text { Teniente mine }\end{array}$ \\
\hline
\end{tabular}

\subsubsection{Annual plan}

The objective of the plan was to ensure the operational continuity and complete the planned developments within the investment scope of mine preparation using strategic planning for the execution of construction activities in 2019. Figure 5 shows the annual scope defined in the plan for the four productive levels. The plan established main and intermediate strategic milestones, infrastructure, civil engineering and development, explosives and ground support requirements, muck management, and the tactics that underpin the strategic planning: all of the above with monthly detail. Moreover, construction yield assumptions were defined together with the construction company by analyzing the historical performance and available resources, as well as operational interference and restrictions of the project sectors.

In sessions to validate and evaluate the final plan, the areas of engineering, geology and geotechnics, and operational excellence participated to voice their concerns, discuss the management of the main issues for the period, and ensure the whole organization was informed. In these sessions, the director of the project actively participated to resolve contractor concerns and be completely involved in project planning. Also, the contractors and management of the productive sectors had relevant participation to coordinate the execution of the activities in the shared areas at the supervisory level. 


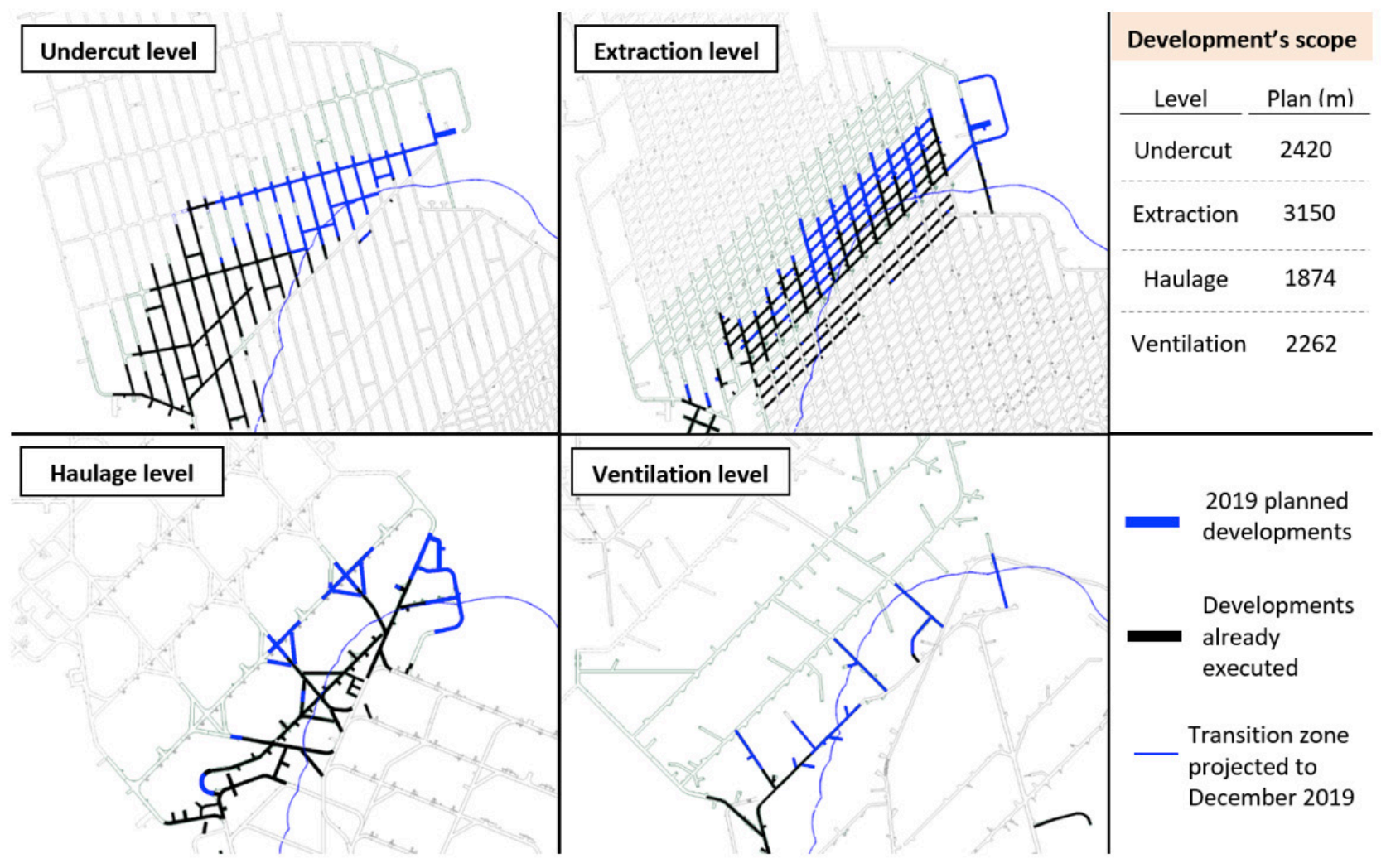

Figure 5 Recursos Norte Project scope of annual plan for developments in production levels

\subsubsection{Pull planning (quarterly plan)}

Pull planning sessions were used to discuss the quarterly plan with the master plan and the annual plan as a basis for the discussion. The project's stakeholders met - from the management area to shift bosses - who through collaborative planning challenged the initial dates established for the intermediate milestones of the project. The above is based on the programming of the activities in view of the critical dependencies and specifying assumptions through the expertise of the field executors. Then, the sequence of activities executed by each area was discussed, analyzed, and agreed on, from the date established in the master plan backwards, according to the duration, available resources, and interactions among the work activities. The above sought to compress and detail the work plan activities. The workshop corresponded to a programming instance during which it was possible to reduce the potential conflict and develop synergy within the team. Figure 6 shows the first work session in April 2019 that covered the April-May-June quarter. On the right is the stakeholders' discussion for each milestone of the plan and on the left is a weekly break down of activities with the dates and people responsible for executing each activity specified.
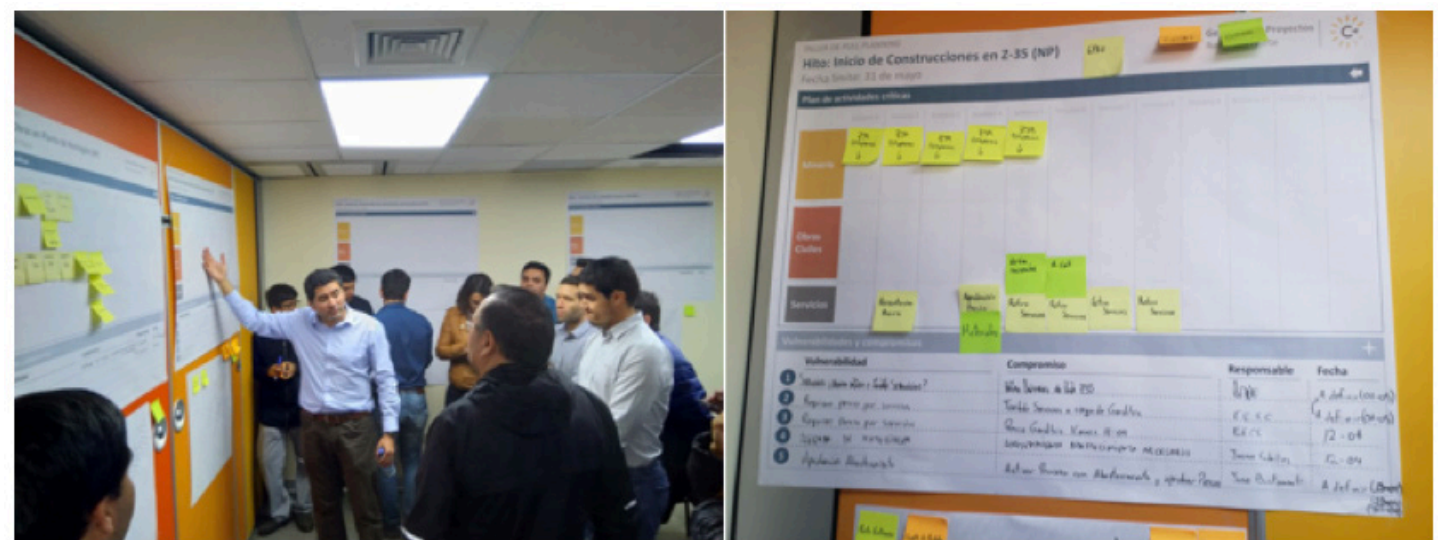

Figure 6 First pull planning session for Recursos Norte project's commissioning 
Table 3 summarizes the main results regarding the intermediate milestones for the commissioning, as well as the modifications to the dates defined initially in the master plan. The third column highlights the time that some milestones were compressed through collaborative planning compared with the initial target date.

Table 3 Summary of the results from the pull planning sessions for the commissioning

\begin{tabular}{|c|c|c|}
\hline \multicolumn{3}{|c|}{$1^{\text {st }}$ Pull planning session (April-May-June 2019) } \\
\hline Milestone & Main improvements & Schedule date setting \\
\hline $\begin{array}{c}\text { Infrastructure } \\
\text { construction (Z-35) }\end{array}$ & $\begin{array}{c}\text { Collaborative planning between mining and service } \\
\text { crews } \\
\text { Directors committed on cost approvals }\end{array}$ & Specified for June 30 \\
\hline $\begin{array}{l}\text { Hydro-fracturing } \\
\text { start }\end{array}$ & $\begin{array}{l}\text { Sequence of PA improved by more coordination } \\
\text { Earlier availability of zones to start drilling }\end{array}$ & (+) 3 weeks earlier \\
\hline $\begin{array}{l}\text { Construction of } 3 \\
\text { muck ore passes }\end{array}$ & $\begin{array}{l}\text { Equipment (raptor) availability and schedule of activities } \\
\text { for the next shifts }\end{array}$ & No changes \\
\hline $\begin{array}{l}\text { Finish construction } \\
\text { of concrete plant }\end{array}$ & $\begin{array}{c}\text { Coordination of activities between developments and } \\
\text { infrastructure crews }\end{array}$ & (+) 2 weeks earlier \\
\hline $\begin{array}{l}\text { Developments in } \\
\text { the undercut level }\end{array}$ & $\begin{array}{l}\text { Improved operation time and blasting rate in these } \\
\text { headings } \\
\text { Plan to increase ore pass availability }\end{array}$ & (+) 2 weeks earlier \\
\hline \multicolumn{3}{|c|}{$2^{\text {nd }}$ Pull planning session (July-August-September) } \\
\hline $\begin{array}{l}\text { Caving area } \\
\text { necessary }\end{array}$ & $\begin{array}{l}\text { Agreed on plan until September with specific blasts per } \\
\text { month to incorporate first drawbell of the project to } \\
\text { production. }\end{array}$ & $\begin{array}{l}\text { Specified for } \\
\text { September } 30\end{array}$ \\
\hline $\begin{array}{l}\text { Infrastructure } \\
\text { construction (Z-35) }\end{array}$ & $\begin{array}{l}\text { Update plan with construction people to improve } \\
\text { activity performance and management restrictions }\end{array}$ & $\begin{array}{l}\text { Specified for July } 30 \\
\text { (-) } 4 \text { weeks later }\end{array}$ \\
\hline Preconditioning & Update position of holes that delay execution & After commissioning \\
\hline
\end{tabular}

\subsubsection{Monthly construction plan}

The pull planning session was used as a basis for the elaboration of the monthly construction program regarding milestone accomplishment dates and requirements, as well as the performance and resources for the operational cycle in each construction activity. During the preparation cycle, the information used from the quarterly plan was updated, the tactics were discussed, and commitments were made with those responsible, regarding dates of completion and impacts of non-compliance. This included the participation of the different areas involved in the project in meetings to review the results of the previous month and milestones. The monthly plan considered:

- Global detail of the project: Detail of the blasts and meters of advance for horizontal and vertical developments, civil engineering and infrastructure, relevant milestones, and vulnerabilities presented using an S-curve graph of project progress and schematic graphics.

- Detail planning by level: Mine preparation program broken down by week also with daily specification, focusing on the requirements and activities to complete relevant milestones and manage vulnerabilities.

- Detail plan of muck extraction: Plan of daily muck tons generated by the blasting plan as well as the daily tons to extract, availability of intermediate ore passes, mucking equipment and extraction routes. 
- Activities in ASZ: Activities inside the ASZ were declared to provide information on the position of the caving front.

- Services and telecommunications plan: Description of the activity program for the month and of special work requests for repair and maintenance with details regarding the engineering, supplies and labor.

\subsubsection{Weekly and future program}

The daily planners from the client and contractor prepared a weekly mine-preparation-activities program with the objective of mobilizing the organization in advance of possible deviations from the monthly plan. The plan was prepared based on the daily control and monitoring and the status of activities compared and contrasted with the updated monthly program. During the week, daily planners had periodic meetings with the different stakeholders of the project to analyze and discuss the results, tactics, restrictions, and vulnerabilities relevant to the interaction of activities in and between levels. Most relevant meetings for collaborative planning were:

- Meetings with mine production area: Collaborative planning instances between contractors from Reservas Norte and Recursos Norte about the activities to execute in the week. Interferences between activities, post-blast isolation sectors, availability of muck ore passes, and mucking routes were discussed.

- Planning meetings between client and contractor: Daily planners maintained periodic meetings during the week to manage planning activities. They also had specific meetings for the elaboration of the weekly plan with a focus on identifying the main deviations, and otherwise, supporting meetings with shift bosses and leaders of each construction department.

- Weekly plan presentation meeting: Session led by daily planners with the participation of the contract administrator, construction managers, shift bosses and leaders of the construction departments. Here, the monthly and weekly results were reviewed; also, deviations compared with the monthly plan and the critical route were discussed. The plan for the next week was agreed on, analyzing restrictions in a window of four weeks to keep the organization aligned with the objectives of the medium-term plans.

\subsubsection{6-hour planning}

Within the mine, short-term planners and shift bosses had daily sessions to review the status of the activities specified in the POD in an effort to react in advance to deviations and specify the monitoring tasks to manage restrictions during the shift. In the operations control room, activities were updated according to their status, through the breakdown of the development cycle, detailing mining equipment, resources, and supplies for the next 36 hours. Then modifications, deviations and restrictions were integrated into the next day's plan.

Figure 7 shows the control board where the activities were updated daily. The board was located in the control room for effective communication with all those involved in project execution. In particular, there was a set of activities to complete each hour for each specific heading or civil engineering activity. Headings were listed on the board according to the development priority and highlighted the day on which their cycles were planned to be completed. 


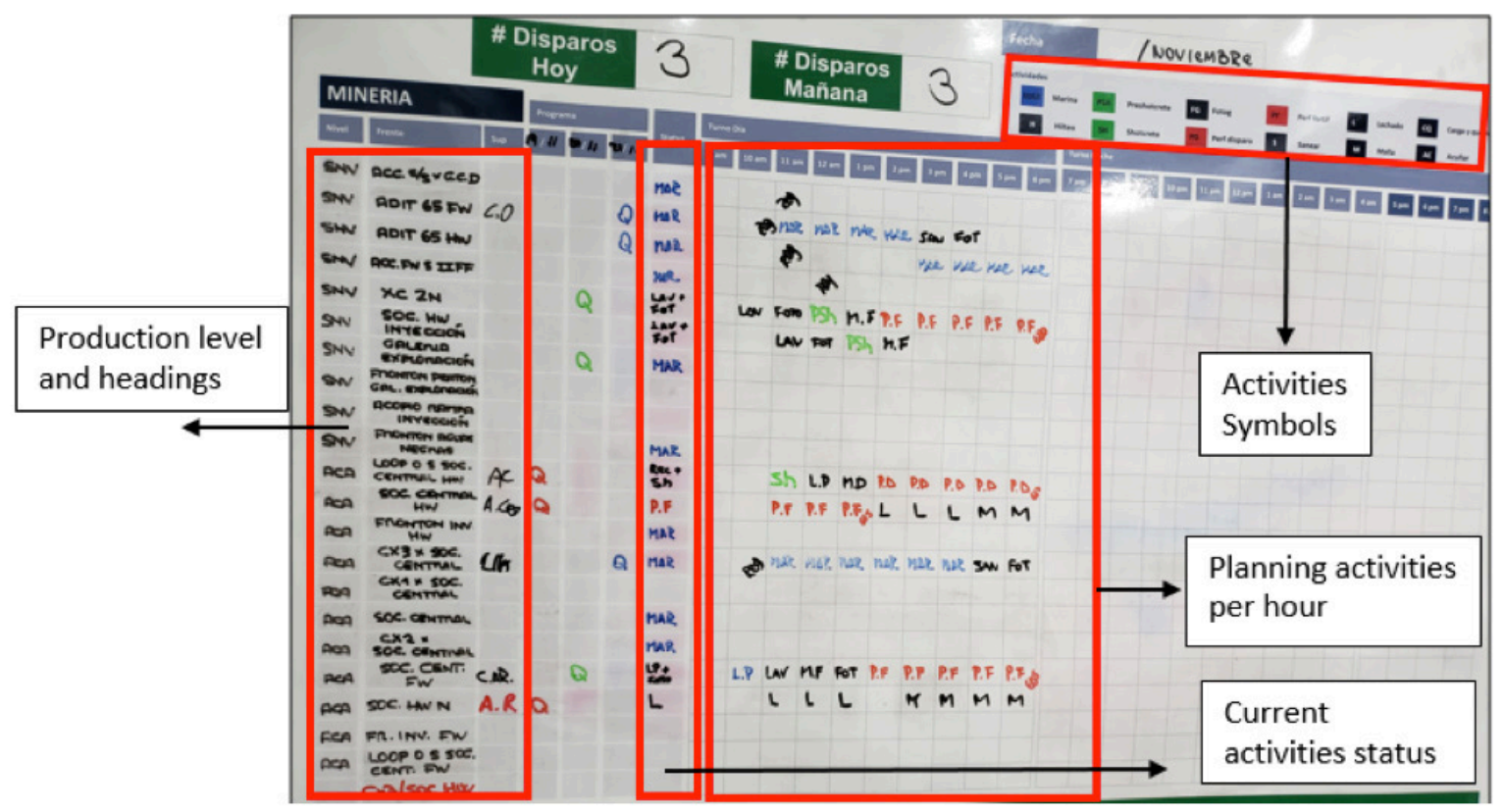

Figure 7 Control board for daily construction developments activities

\subsubsection{Plan of day (POD)}

Starting each shift, the shift boss from the contractor led a meeting and described the POD activities for the supervisors and those involved in executing the activities. In the session, the results from the previous day were reported, deviations from the plan were discussed and corrective actions defined. Each construction area described the status of their planned activities, declared their requirements, and analyzed the best manner to execute activities in interaction zones.

\section{$4 \quad$ Lean construction tools}

To align the objectives to achieve in the project, FRS were carried out which generated a base line of critical key performance indicators to control and challenge through continuous improvement. Of that base line, values that represented the best performance defined the aspiration for which the contractor, client and stakeholders worked as a team to obtain the results. FRS results permitted the most accurate LC concepts to be defined and applied to the project and were used to support continuous improvement for project commissioning.

\subsection{Problem resolution sessions}

In these sessions, adapted from the concept of root cause analysis/five "whys", complex problems that could not be solved in regular meetings were managed with a team of people specifically related to these problems. The session had a structure of plan, do, control and act from lean methodology. Steps to follow were:

a. Define the problem identifying if one of the actual standards is applicable.

b. Establish the objective of the session that must be specific and measurable for further monitoring.

c. Breakdown the most relevant facts and observations to be shown as evidence of the problem. In addition, identify a KPI associated with the problem describing the impact of no resolution.

d. Brainstorm about the possible direct causes of the problem. 
e. Apply the five whys methodology for each cause to identify the root cause.

f. Formulate a work plan for each root cause listed by priority in a matrix identifying people responsible and completion dates.

g. Monitor the work plan in a second session defined by the participants to indicate the status of completion. Participants must define if a third session is necessary for unsolved root causes.

h. Ensure solution is standardized as a last step and someone has committed to its monitoring and control.

\subsection{Sprints}

Based on the concept of concurrent engineering, these sessions allowed a quick response to be generated when the progress of the work was halted or did not progress as planned. In the initial session, people related to the problem or with experience regarding the problem were asked to make immediate decisions and identify actions to resolve the problem. In one-hour daily meetings all efforts were concentrated on solving the problem as soon as possible.

\subsection{Construction standards, management, and coaching tools}

- Construction standards: Assured consistency and efficacy in the execution of a specific activity as a base to further improvements and reduce variability.

- Performance dialogue: In this instance, the most critical problems to be solved were identified from a key indicators board presented to the area leader, commitment compliance was evaluated, and the critical activities to execute during the day were determined.

- One-to-on Coaching: A development plan for each department's leader was defined to enable continuous improvement for each team. In the sessions, internal KPIs were evaluated and discussed.

- Process confirmation: Sessions that allow gaps in critical competences to be identified and those competencies developed. Role confirmation allows opportunities to be identified in management systems that impact results.

\section{Main key performance indicators and overall results of the commissioning}

Figure 8 shows the results and KPIs for developments, civil engineering and infrastructure constructed from January to September in 2019 as compared with the monthly, annual, and master plan. The master plan started in April. 


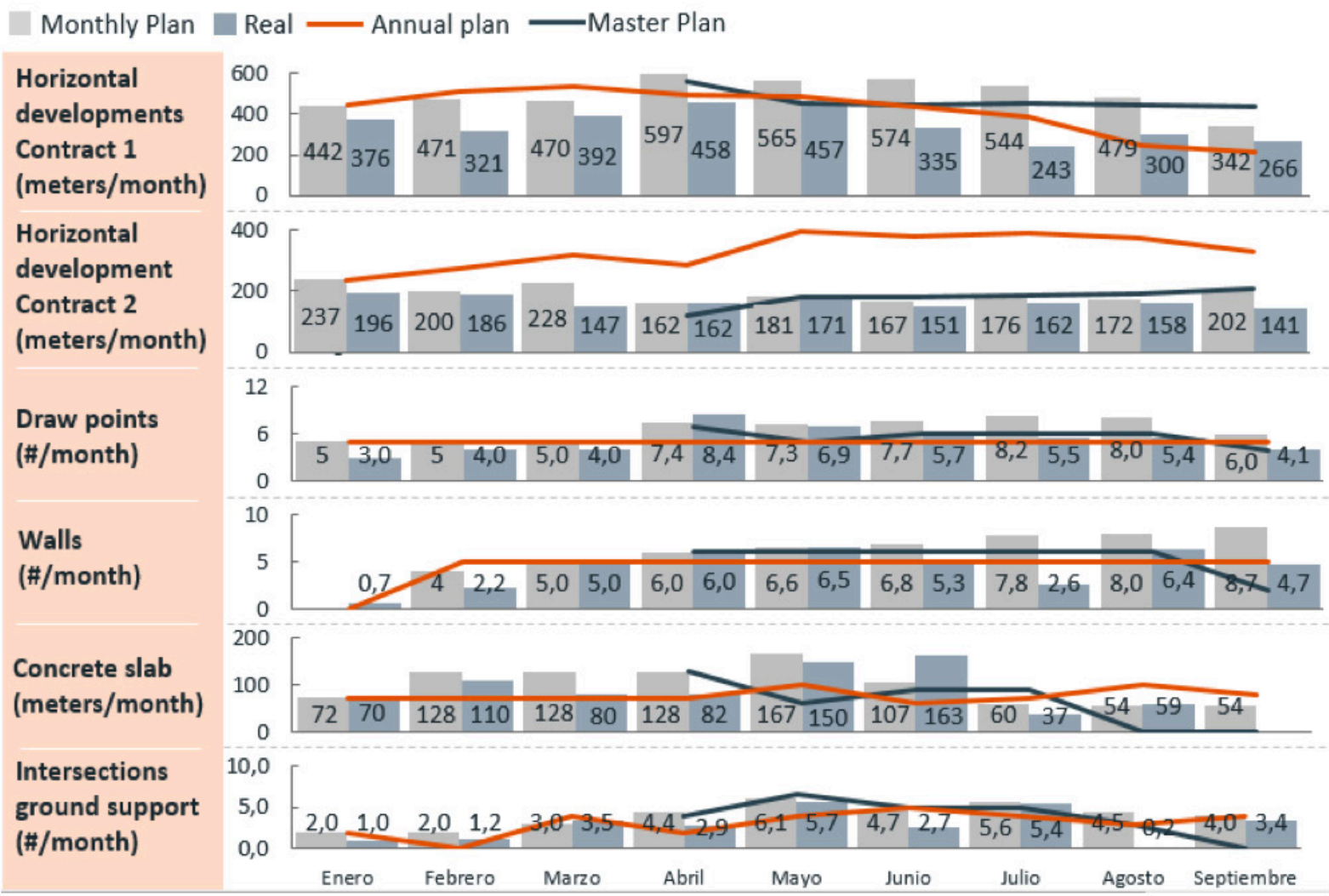

Figure 8 Overall results of the mining construction activities in 2019 for the Recursos Norte Project

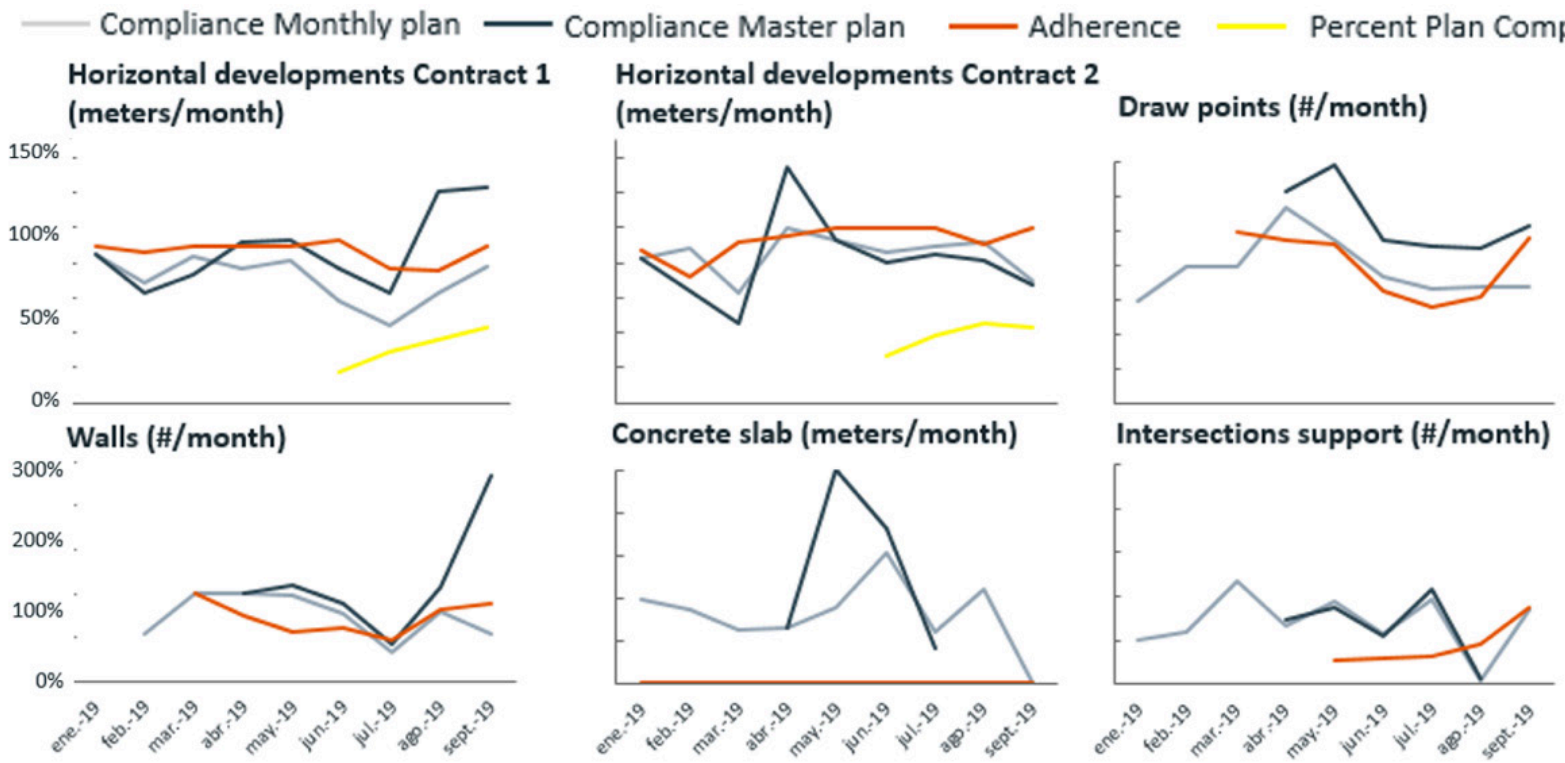

Figure 8 Overall results of the mining construction activities in 2019 for the Recursos Norte Project (continued)

Results obtained for contract C1 show differences in comparison with the monthly plan requirements, but good compliance with the development rates and civil engineering established in the master and annual plans. The main differences with the plan were caused by the block of the planned headings for the presence of muck from previous activities, low ore pass availability and poor management of resources and people by the contractor. The results for contract C2 show good performance in comparison with the monthly and master plans. The differences with the annual plan were caused by unexpected rock burst events in the haulage level that forced each blast to be divided in phases, which implied a lower advance rate but a similar operational time to a regular blast. In addition, at the ventilation level a sector flooded that added activities before executing the blasting, which reduced the number of headings available. 
The previous causes of lower performance were considered in each monthly plan as restrictions or vulnerabilities with high priority of be managed during the next month. The monthly plan always sought to defy the requirements established in the medium-term plans. For the contract $\mathrm{C} 1$ a difference between monthly planned and real values was observed, mainly caused by poor management of the contract administrators from the contractor's side and poor fulfillment of commitments.

The three KPIs defined as completion, adherence, and percent plan complete measure the percent of activities executed against those planned. The completion indicator only considers quantity in the requirement, while adherence considers the specific heading where the activity must be executed. A more demanding indicator is the percent plan complete that considers the location and temporality of the executed activity. This KPI was only applied to the horizontal developments from June 2019. Results show that development activities had a higher adherence as compared to civil engineering activities, whose execution was conditioned by the late delivery of the planned headings from previous mining activities. In general, the percent of the activities executed according to the master plan was near $100 \%$, with some peaks that compensated for the performance from previous months.

\section{Conclusions}

The strategic planning implemented to manage the commissioning milestone allowed the main objective to be achieved, which was to incorporate the first drawbell into production 15 months before the date initially established. At the same time, the continuity of operations was maintained establishing a harmonious advance of the mine preparation activities and the caving front. The LPS provided a framework for the planning cycle that caused fewer problems that required firefighting, a more predictable mine preparation plan, and easier communication among stakeholders. Finally, the main result of applying LC tools was the increase of effective operational time from about 3 to 5 hours.

Applying LPS and LC tools together resulted in several benefits for the organization that could be applied continuously in the following phases of the project. These benefits included a traceable master plan communicated to all levels of the organization detailing the critical route and all the key activities to execute, a sustained and validated base of resources and equipment for each contract activity, expanded knowledge and learning shared among project teams, and specific control and monitoring tools for the progress of the work and management of restrictions.

\section{References}

Ballard, G 2000, 'The last planner system of production control', PhD thesis, University of Birmingham, Birmingham.

Ballard, G \& Howell, G 1998, 'Shielding production: essential step in production control', Journal of Construction Engineering and management', vol. 124, Issue 1, pp. 11-17.

Leal, M \& Alarcon, L 2010, 'Quantifying impacts of Last Planner implementation in industrial mining projects', in proceedings of the 18th International Conference of the International Group for Lean Construction, Haifa, pp. 508-527.

Morales, E \& Díaz, G 2008, 'Tunneling and construction for 140.000 tonnes per day - El Teniente mine - Codelco Chile', in H Schunnesson, E Nordlund (eds), Proceedings of MassMin 2008, Lulea, Sweden, pp. 83-86.

Mossman, A 2017, 'Last Planner: $5+1$ crucial \& collaborative conversation for predictable design \& construction delivery (Dec 2017)', The Change Business Ltd. 